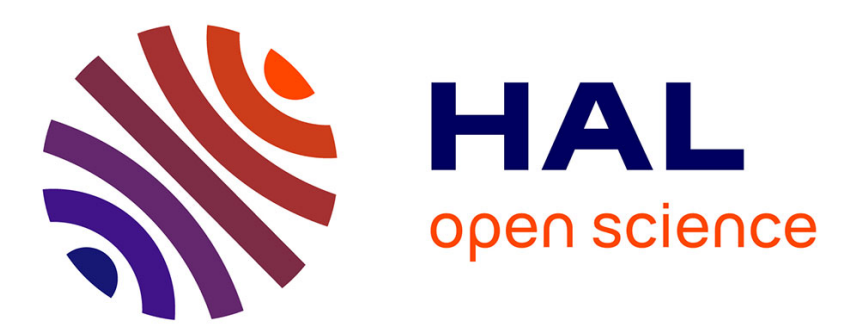

\title{
Actuality and possibility: On the complementarity of two registers in the bodily constitution of experience \\ Gunnar Declerck, Olivier Gapenne
}

\section{To cite this version:}

Gunnar Declerck, Olivier Gapenne. Actuality and possibility: On the complementarity of two registers in the bodily constitution of experience. Phenomenology and cognitive sciences, 2009, 8 (3), pp.285305. 10.1007/s11097-009-9128-4 . inserm-00916707

\section{HAL Id: inserm-00916707 https://www.hal.inserm.fr/inserm-00916707}

Submitted on 10 Dec 2013

HAL is a multi-disciplinary open access archive for the deposit and dissemination of scientific research documents, whether they are published or not. The documents may come from teaching and research institutions in France or abroad, or from public or private research centers.
L'archive ouverte pluridisciplinaire $\mathbf{H A L}$, est destinée au dépôt et à la diffusion de documents scientifiques de niveau recherche, publiés ou non, émanant des établissements d'enseignement et de recherche français ou étrangers, des laboratoires publics ou privés. 


\title{
Actuality and possibility:
}

\section{On the complementarity of two registers in the bodily constitution of experience}

\author{
Gunnar Declerck and Olivier Gapenne \\ UTC - Costech/CRED
}

\begin{abstract}
The purpose of this paper is to demonstrate the usefulness of the concept of possibility, and not merely that of actuality, for an inquiry into the bodily constitution of experience. The paper will study how the possibilities of action that may (or may not) be available to the subject help to shape the meaning attributed to perceived objects and to the situation occupied by the subject within her environment. This view will be supported by reference to empirical evidence provided by recent and current research on the perceptual estimation of distances and the effects brought about by the use of a tool on the organisation of our perceived immediate space.
\end{abstract}

\section{Keywords}

Possibility, Affordance, Perception, Lived body, Constitution of space 


\section{The status of the lived body and the question of possibility in psychology}

The use of traditional (mainly Aristotelian) metaphysical categories such as the actual and the possible may raise a few eyebrows, especially within a research context that is equally sensitive to the phenomenological question of the lived body as it is to the body's strictly physical dimension (i.e. its substratum, in Ricoeur's sense of the term - that without which there would be no subjective experience, the 'sine qua non' ${ }^{1}$ ). The relevance of these conceptual resources may seem remote from the interests of researchers working on the naturalisation of experience, or indeed to anyone interested primarily in a phenomenological approach to the process of naturalisation. Yet it is worth noting that Aristotelian metaphysics - to which we owe such notions as actuality (energeia) and possibility (dynamis) - may reasonably be given a phenomenological interpretation to the extent that it erects a whole range of categories that are deemed an integral part of our spontaneous experience of the world into full-blown metaphysical concepts ${ }^{2}$. Indeed, far from viewing them as metaphysical notions that bear no relation to the world which we commonly know and perceive, such concepts are better construed as schemas that help to describe the way in which we ascribe intelligibility to the diverse realities with which man engages. On the other hand, we may note that the usefulness of these concepts is in fact tacitly acknowledged in contemporary psychology and cognitive sciences more generally - rooted as such categories are in ordinary language and in our everyday categories of thought. As evidence of their use, we need only consider the current standing of the Gibsonian concept of affordance - which literally corresponds, in the case of perceptual experience, to an actually perceived possibility, which is used in a wide range of disciplinary contexts, from cognitive psychology and neuropsychology to design. Such is the justification for this exercise in radical conceptual clarification.

First of all, it is important to clarify the significance of the concepts of the actual and the possible in the context of an inquiry into the nature of the lived body. A brief history of the question of the body might help to shed some light on this matter. The question of the 'nature' of the body of the perceiving agent was initially raised as a primarily philosophical issue, especially within an ontological context of inquiry (say, the nature of the body as opposed to the nature of the soul or of the spirit). More recently, the issue has been addressed as a phenomenological issue concerning the modalities of appearance (the different phenomenological modalities by means of which consciousness experiences the body). By contrast, the question of the body has never been raised as such by researchers within the human sciences, and in psychology in particular, though in recent years interest in the issue appears to be growing. This is not altogether surprising, since there was until recently a ready answer for the question: the only body of the human being is the organism, the physical substance, and so anything that is experienced by a subject as her body is construed as a representation of this physical body, or at any rate as a unified percept constructed via different forms or perspectives by means of which the physical body is perceived.

This representationalist conception of the body (the predominant view in psychology since the dawn of the discipline) contrasts sharply with another conception - the 'constructivist' view. Constructivism approaches the body experienced by the subject not as the reflection (however distorted) of some pre-existing reality, but as the original product of the mind's work - a means devised by consciousness of making its inscription intelligible to itself within its own specific modes of rationality. By inscription we mean both the perceptible inscription of consciousness (it is as a body that it is perceptible to another consciousness) and its practical inscription (as a body it can bring about change in things) within a being.

Notwithstanding these differences (which in some respects derive from the nature of the referent of the lived body), both conceptions share one common view, namely that the body of the conscious subject is construed as a reality which is by some means or other actual. Indeed, the lived body may be conceived either as a perceptual representation of the physical body or as a reality constructed by the mind, though not the reflection of a pre-existing given. But in both cases the body is an actual image constituted within the living present. What the body actually is thus exhausts itself immediately within the here and now.

The conception of the body defended in this paper is a flat refutation of this view, or at any rate of its unilateral approach to the issue. Instead, we will argue for a complementary approach in conjunction with another mode in which the body makes itself available: the horizon of the possible. On a strictly phenomenological/experiential level, the way in which the body is present to the subject, the way in which the subject experiences her bodily constitution, is not reducible to the physical situation as it is in actual fact. For the subject for whom action is a prerequisite for perception, and more fundamentally for life, the body, far from being merely what it is actually - its state, its position, its shape, its situation - is better construed as an available

\footnotetext{
${ }^{1}$ See Changeux \& Ricœur (2000).

${ }^{2}$ This is the guiding principle of Heidegger's reading of Aristotle. See in particular Heidegger (1931). See also Patočka (1995), especially the section entitled The phenomenology and ontology of movement, pp. 29-30.
} 
power, and more specifically as an intervening power whose availability is an object of trust - of almost blind trust. The actual position of the body, the way in which it is situated in space, tends, for the subject, to acquire meaning from the various possibilities to which the given is open. The subject experiences the configuration of her body not by observing the position of the various parts of her body within a given reality, but as an opening onto the possible. The problem that needs to be addressed in order to provide a satisfactory account of the nature of the body (such as the subject experiences her body) is therefore the actuality of the possible: how that which is possible, that which is 'only' possible, can in some sense be actual, or present - how it might haunt the actual.

The inclusion of the notion of possibility within the framework of empirical psychology has always been a deeply problematic issue because of the primarily actualist nature of the ontology upon which psychology is founded: that which exists is only that which is given, or amenable to observation, or that which is in the process of being. So that which is not actual (the past, the future, the realm of the imagination) is ontologically dependent upon processes that are actually in motion, which is tantamount to reducing being to the present. In this sense, psychological materialism (i.e. the reduction of cognitive/psychological phenomena to physicochemical, and especially neurophysiological, processes) merely constitutes in fine a means of reasserting this fact. The inclusion of the notion of the possible within this framework will thus tend to distort the idea: if taken seriously, the possible may precisely be defined as that which is not currently in process, indeed as that which need not be in process in order to be and exist, but which nevertheless exists in the form of a latency, at the horizon of the current situation.

Possibility has usually been interpreted in psychology as a representation. Typically, the subject is aware of (or rather: is open to) her possibilities to the extent that she has a (mental/cerebral) representation of them. By this conception, it is precisely to the extent that possibility is inscribed within the perceiving organism in the form of a representation that it can be said to be real.

The recent theory of the mental simulation of action used to account for the practical/functional signification with which objects and structures within our immediate environment are perceived (tools, typically) may reasonably be interpreted as just one such attempt to reduce the possibilities available within the horizon of the subject's perceptual experience to the actualisation of such representations ${ }^{3}$. By this conception, the factor which gives it an operative status within the constitution of perceptual phenomena is the mental simulation of the deployable action ${ }^{4}$ : if $I$ can perceive that the object in front of me is within reach of my hand, if it presents itself to me as something that I may grasp, it is because a cognitive process to which $I$ am not privy is currently actualising this possibility. Here, the role of the notion of simulation is evidently to ascribe an actuality, and thereby a reality, to the possibilities which the perceived ambient world, by virtue of its organisation and meaning, appears to make available. The underlying reasoning of the theory might be described in the following terms: if a human agent perceives her environment while remaining open (be it consciously or not) to the range of possible interactions with, and investment in, that environment, it is because she is already engaged in the process of actualising these possibilities. If this were not the case, these possibilities could not participate in the interpretation of their objects of perception: the perceived world would merely constitute a set of objects devoid of instrumental use and practical meaning. Therefore, since the perceiving agent does not enact the possibilities at her disposal through an effective motor actualisation, it means that they are actualised by pre-motor and virtual means - that the perceiving agent simulates them as mental representations.

The use of the concept of representation to account for a subject's perceptual experience of the world, informing her of what she can or cannot not do, has been severely criticised both in psychology ${ }^{5}$ and in philosophy (especially the phenomenologies of existence). One particular criticism from phenomenology concerning the reduction of the possible to a representation of the possible is that a possibility which I think (whether represented or mentally stimulated) is not a possibility in which I am engaged and may live: I can engage and live in a possibility without thinking about it (i.e. without having a mental representation of it), just as I can mentally envisage a possibility without actually living or experiencing it, i.e. without the possibility of it actually involving me. It is not as a result of representing herself or by having the representation of what she can do that the subject can be said to have this 'possession' with respect to her practical aptitudes or possibilities, that she experiences herself as disposed to or in the process of, as being able to.

What phenomenologists commonly refer to as the 'I can' fundamentally eludes representation. For J. Patočka or M. Merleau-Ponty, it is primarily the motor condition which enables the individual's availability to the possible, which allows for a life within the possible which characterises human existence, and which means that for a human being what is primarily actual is that which is not actual. It is not in the mental representation of

\footnotetext{
${ }^{3}$ See in particular Coello \& Delevoye-Turrell (2007) and Jeannerod (2001).

4 'Action simulation and associated predicted sensory consequences may represent the underlying principle that enables prereflective representations of the body for space categorisation and selection for action'. (Coello \& Delevoye-Turrell, 2007).

${ }^{5}$ See in particular Turvey \& Shaw (1979) on the notion of epistemic mediator. See also Turvey (1974).
} 
a reality that is actually absent that the primary relation of man to the possible must be sought, but in action, in movement, which, as a living movement, is intrinsically finished and in contact with its end (or, to use Scheler's term, its terminus ad quem ${ }^{6}$ ) before it has effectively reached it. Man's relation to the possible arises primarily out of the fact that he is engaged in a perpetual moving-towards, in a state of anticipation ahead of his actual situation $^{7}$. And it is just this tension toward the possible that gives meaning to its actuality, that makes it a situation $^{8}$. In other words, there is already the suggestion of a kind of opening onto the possible in what MerleauPonty, in The Phenomenology of Perception, described as motor intentionality. Of course, to allow movement to shoulder the burden of man's opening onto the possible, of what Heidegger called our existentiality, requires that we posit a movement which does not consist of a succession of positions of a body in motion, a succession of punctual presents, but rather immediately conveys a temporal thickness, a projective movement.

On the face of it, there may appear to be little reason to doubt the relevance of this approach, and it may seem reasonable to use it in the context of a philosophical and phenomenological inquiry. Its re-appropriation in the context of an attempt at naturalisation, or at any rate within the terms of an inquiry that is receptive to the evidence provided by empirical data, nevertheless remains deeply problematic. Furthermore, if it is worth noting that the individual experiences her body not merely as an actual given reality but also as a horizon of available practical possibilities, it is equally important to note that the ambient world such as it offers itself to experience is embedded in a relation of correspondence with respect to these possibilities. As Merleau-Ponty put it, my body and the world form a system ${ }^{9}$. In a sense, it is just this relation of correspondence that the Gibsonian concept of affordance is designed to articulate ${ }^{10}$. The experience of the ambient world as a system of affordances is shot through with a 'knowledge' of the possibilities of interaction with things. The question of the prerequisites for an experience of the ambient world as a system of affordances ${ }^{11}$ thus raises the more general issue of knowing how the practical possibilities that are available to the perceiving agent can subtend the process of constitution of the ambient world, the constitution of its organisation, its structure and its shapes, as well as the pragmatic semiotics that oversee the meaning through which things are envisaged - to take on what we shall refer to as a hermeneutic function within this process of appresentation.

The suggestion made by Coello \& Delevoye-Turrell (2007) to distinguish the notions of experiential body and functional body could be viewed as an attempt to account for the dimension of possibility governing experience. However, the point we wish to emphasize is that the authors presuppose that a cognitive system must necessarily simulate the deployable activity (the possibility of action) for the elements within the perceptual field that are the object of a conscious experience to be 'interpreted' through reference to this activity (i.e. broadly speaking construed as affordances). In this conception of "possibility", the subject only has an experience of what she may or may not do when she perceives the world because a process of simulation (and therefore a certain form of actualization) of these possibilities is under way. The proposition of Coello \& Delevoye-Turrell

\footnotetext{
${ }^{6}$ Scheler, Philosophischer Anzeiger, vol. II (1927), quoted in Patočka (1995), p.37.

7 'Our existence is essentially bodily, embodied, and our lived body, insofar as it is a living body, insofar as it is a body that is able to move, insofar as it is a body over which we have control, is the foundation of any life of experience. Control over the body is a form of being which constitutes an understanding of its most fundamental possibilities, without which a life of experience, which understands itself, would not be possible. It is for this reason that we must insist that our existence is what it is not because movement inherently belongs to it, but because it is movement by its very nature'. (Patočka, 1995, p.107). See also p.25.

${ }^{8}$ To quote Patočka : 'Our action revolves within horizons of possibility; an action is ahead of itself in the realisation of an anticipated possibility before returning from the possible back to the actual. This being-whichis-ahead-of-itself in horizons is characteristic of human normality, whereas the progression from one actuality to the next characterises certain pathological cases of our relation to the world.' (Patočka, 1995, p.68)

${ }^{9}$ See Merleau-Ponty (1945), p.237.

${ }^{10}$ Our use of the notion of affordance is essentially phenomenological inasmuch as it is used to describe the way in which a man (or an animal) has a spontaneous perceptual experience of his ambient world, i.e. as a system of possibilities. We therefore contest Gibson's realist use of the notion. Warren (1984) provides a useful account of Gibsonian realism, insisting that affordances are founded on the physical properties of the animal and of the environment and that they exist whether or not they are in fact perceived. To this extent they do not vary in accordance with the needs or the state of the perceiving agent.

${ }^{11}$ Here we argue that the world is spontaneously perceived by the individual as a system of affordances, though everything is dependent on an individual's perceptual attitude. An individual may adopt an 'analytical' attitude or merely target the sensible dimension of phenomena (thus ceasing to perceive the ambient world as a system of affordances). But in an individual's daily pre-reflective perceptual experience of the world, objects present themselves as a collection of affordances; they immediately present a functional meaning: in other words, the individual perceives what she may be liable to do with objects. By our conception, this is an irrefutable phenomenological fact.
} 
(2007) is possibly relevant for an account of the cognitive process that occurs in tasks involving estimation, such as an estimation of the reachability of objects situated within a subject's visual field. But in our view, it is insufficient to account for the practical/functional signification with which objects and structures within our immediate environment are perceived, whether or not the individual is engaged in a process of evaluation of her possibilities. The issue is not solved by emphasizing the likelihood that such a process of mental simulation of possibility (in this case the deployable actions) or the emulation of the consequences of actions are nonconscious. From our point of view, the issue here is not to establish whether the activity of simulation of the deployable action is a content of experience, the object of a conscious grasp (however 'confused'), or if it is subconscious (i.e. the subject is not aware of it), but to determine if the constitution of the experienced world insofar as it conveys functional significations that pertain to an individual's possibilities (particularly practical possibilities) has to be necessarily subtended by a process of actualisation (whether virtual or mental) of these possibilities. In other words, does the possible have to be actualized for it to perform a hermeneutic function in the construction of perceptual experience (i.e. the construction of the world perceived as a system of affordances)?

The hypothesis argued for in this paper is that it is not by means of mental representations (which might be gradually instantiated in memory, particularly dispositional memory ${ }^{12}$ ) that the individual 'is aware' of what she can do, but by the bringing into play of an interpretation of the ambient world and of the situation occupied by the subject within that world, in other words an anchoring within that milieu which means that the milieu presented in the perceptual field takes on a practical meaning. In other words, the 'knowledge' that an individual has of her possibilities (primarily her possibilities of bodily intervention) is fundamentally an enacted form of knowledge, which may therefore have no other reality but an interpretative schema which conditions the meaning (especially the functional/operational meaning) with which the ambient world is made available to perception. In this sense, it is perhaps misleading to speak of knowledge in this context, because strictly speaking the individual does not have any 'knowledge' of her practical possibilities: if she has a relation to what she is able to do, it is only to the extent that she relies on the availability of her abilities, which are never accessible as such but always involved, appealed to, in the interpretative process that enables the world to appear as a system of summonable, usable structures - in short an organisation of affordances.

This issue will be initially clarified by reference to the specific case of the spatiality of the ambient world, the bringing-about of a world constituted by objects disposed partes extra partes and assigned to particular places - which may be considered, as we shall see, as a means of interpreting the objects of perception by considering the possibility of accessing them.

\section{The spatial organisation of the ambient world and the hermeneutic function of possibilities}

Ever since Berkeley's celebrated essay on vision ${ }^{13}$, many theorists of perception have defended the view that the spatiality experienced by a subject (primarily through visual means), especially the perception of the distance of objects, proceeds from an interpretation of things or sensations through reference to the possibility of movement. By this conception, the spatial configuration within which the environment is apprehended, the configuration of things in a depth that escapes towards a given horizon, is the expression of a way of referring that which surrounds us back to our capacity to access it - a way of seeing things that brings to life the gap which separates us from them, i.e. a means of interpreting them from the standpoint of the fundamental disposition of motor functions.

In the first section of Matter and Memory, Bergson noted that the aspect of the objects pertaining to the visual field (as well as the intensity of sounds or smells) is an expression of the more or less immediate access that we have to them. He interpreted perceived distance as something organised according to a metric of the power of action ${ }^{14}$. Similarly, in his analysis of the sense of spatiality, in particular of depth, Merleau-Ponty

\footnotetext{
${ }^{12}$ See Thomas (1984), quoted in Paillard (1994).

${ }^{13}$ Berkeley (1709). For an account of Berkeley's theory as a precursor of issues in contemporary psychology, see Pacherie (1997).

14 'I observe that the dimension, shape, and even the colour of external objects alter according to my body's relative proximity to them, that the strength of smells and the intensity of sounds tend to increase or decrease as a result of distance, and finally that this distance primarily constitutes in itself the extent to which ambient objects are so to speak protected from the immediate action of my body. As my horizon widens, so the images within my surroundings appear to be outlined against a more uniform backdrop and to become indifferent to me. The objects circumscribed therein are distinctly positioned in accordance with the relative ease with which my body is able to touch them and to move them. In the same way as a mirror, they return its potential influence to my
} 
concluded that 'locations within space are not to be defined as objective positions in relation to the objective position of our body; rather, they inscribe around us the variable reach of our intentions or of our movements ${ }^{, 15}$. Simondon likewise argued that 'the milieu is perhaps primarily to be defined as the entire range of the organism's (i.e. the lived body's) potential movements rather than the dimension which organises objects ${ }^{, 16}$.

We will argue that this conception of the nature and sense of perceived space is supported by a number of recent empirical observations drawn from research in psychology into the consequences of the use of tools on the spatial organisation of the visual field and the estimation of distances. This point requires a more extensive discussion.

\subsection{Ecological psychology and the role of capacities in the constitution of the perceptual field}

In psychology, it is probably J.J. Gibson's theory of affordances that provides the most comprehensive, and perhaps the most radical, account of the view that the aptitudes of the perceiving agent (her potential relation with the world, as well as her motor, manipulatory and instrumental aptitudes) contribute to the structuring of the perceptual field and to the constitution of the meaning of perceived objects. Gibson defined affordances as the range of activities made available to the perceiving agent within her environment insofar as she has the use of certain aptitudes and capacities for action ${ }^{17}$. The thesis underlying Gibson's theory of ecological perception rests on the claim that it is just such affordances which a man or an animal more generally, is liable to perceive in the spontaneous attitude described in phenomenological terms as everyday, pre-reflexive or ante-predicative. Far from construing it as a set of perceptible qualities that require interpretation, the ambient world is immediately perceived by a man or an animal as a system of affordances ${ }^{18}$. Furthermore, the subject's conscious awakening to the possibilities made available to her within her environment is not the product of some 'high-order' cognitive activity (or in the event that it is, it will only be a mode of access derived from the affordances) that supposedly deduces the range of deployable actions from the available sensory information (for example by stimulating them mentally). Rather, it is derived from a direct (i.e. unmediated) perception $^{19}$ : the perceptual apparatus already has an organisation and a selectivity built into it that allows for the detection of structures (such as optical patterns in the case of vision) corresponding to typical affordances in sensory flow, without the need for any other form of informational processing. Turvey \& Shaw (1979) coined the term 'effectivities' to describe the properties of the perceiving agent to which the affordances correspond - in a sense the properties or aptitudes to which these affordances are "addressed" ${ }^{20}$ (for example, the ability to walk or to stand in the case of the affordance of walking or the orthostatic posture offered by rigid horizontal surfaces).

Various studies of the perception of such affordances have underlined the determining role of the perceiving subject's bodily dispositions. Some of these have shown for instance that the perceptual judgements pertaining to the possibility of sitting down (Mark, 1987; Mark \& Vogele, 1987), of climbing stairs (Warren, 1984), of walking through apertures (Warren \& Whang, 1987), of crossing a road without risking being run over (Oudejans et al, 1996) or of reaching out for objects (Solomon \& Turvey, 1988; Carello et al., 1989) were not solely determined by so-called 'objective' properties within the environment (the objective height of chairs or

body; they organise themselves according to my body's increasing or decreasing powers'. (Bergson, 1896, p.15; see also pp.28-29).

${ }^{15}$ Merleau-Ponty (1945), p.168.

${ }^{16}$ Simondon (1964-1965), p.286. For similar interpretations, see also Heidegger (1927), paragraphs 22-24, especially p.102; Sartre (1943), p.573; Poincaré (1907), p.82; Ruyer (1952).

${ }_{18}^{17}$ See for example Gibson (1979), p.127.

18 'Psychologists assume that objects are composed of their qualities. But I now suggest that what we perceive when we look at objects are their affordances, not their qualities. We can discriminate the dimensions of difference if required to do so in an experiment, but what the object affords us is what we normally pay attention to. The special combination of qualities into which an object can be analysed is ordinarily not noticed' (Gibson, 1979, p.134).

${ }^{19}$ In Gibson's work, the "direct" character of perception appears to mean that the access that an individual (whether man or animal) has to useful information is not necessarily mediated by a process that involves the treatment of this information by the elaboration of a mental representation. Gibson's concept appeared primarily to serve a critical function, and was mainly designed to clarify his position in response to opponents of his theory.

20 'The effectivity of any living thing is a specific combination of the functions of its tissues and organs taken with reference to an environment. By this conception, an animal is defined as a set of effectivities, or an effectivity structure' (Turvey and Shaw, 1979, pp.205-206). This definition is designed to supplement Gibson's description of affordance: "the affordance of anything is a specific combination of the properties of its substance and its surface taken with reference to an animal' (Gibson, 1977, p. 67). 
steps or the objective width of openings), but were also influenced by the ability to act or by the bodily conformation of the perceiving subject. Furthermore, the interindividual variability of judgements concerning affordances was found to be relative to differences in bodily dispositions (Warren, 1984; Mark, 1987). Warren (1984) showed that the maximum height of a step deemed to afford climbability could be expressed by a factor corresponding to the constant proportion of leg length. Mark \& Vogele (1987) made a similar observation concerning the maximum height of chairs estimated to afford sitability ${ }^{21}$.

Let us return now to the central object of this section - namely the experience of space. A number of recent studies have drawn very similar conclusions concerning the estimation of distance. They suggest that the estimated or perceived distance could, in a similar way, depend on the disposition of the perceiving subject to grasp objects. Proffitt et al. (2003) showed for instance that the egocentric distance to a given object was perceived or estimated to be greater when the observer was made to carry a heavy load. The same observation was made by Witt et al. (2004), but here the addition of the load only influenced the distance perceived by the agent between herself and a given object if the estimation was accompanied by the anticipation of the effort associated with having to walk up to the object. In other words, if the observer anticipates having to throw a projectile towards the object whose distance from her is the object of her estimation, the fact that she is carrying a load has no bearing on the process of estimation. The conclusion in this case was that the effect of anticipated effort on perception is determined by the action which the observer anticipates having to perform ${ }^{22}$. Following on from Proffitt et al. (2003), Witt et al. (2004) concluded that 'the process underlying perception of egocentric distance combines the optically specified geometry of spatial layout with current behavioural goals and the potential to achieve these goals', and that the perceived distance is therefore 'not only a function of the optical variables to which it relates, but it is also influenced by the actions we intend to perform and the effort associated with those actions, ${ }^{23}$.

\subsection{The influence of the use of tools on the spatial organisation of the perceptual field}

Several recent studies devoted to the effects brought about by the use of tools on spatial organisation and the estimation of distances also provide a number of significant observations concerning the relation between perceived space and the practical possibilities available to the perceiving subject.

Many clinical, behavioural and neuropsychological observations have shown that several varieties of spatial reference frames were used to organise the perceptual field and to guide our actions. In particular, the individual appears to organise her ambient perceptual space by means of a near (peripersonal) space and a far (extrapersonal) space. Most psychologists concur that the significance of this distinction is primarily functional: an object situated in the subject's peripersonal space is an object that is within reach and may be grasped manually without the need to move. By contrast, the case of an object situated in extrapersonal space, which is out of reach, implies that the object cannot be reached and grasped without walking towards it - unless the individual has the use of a tool which gives her a direct access to distant zones. Such, at any rate, is the meaning of the distinction from the point of view of the potential of the individual's practical engagement. Evidence for this particular conception is provided by the fact that the dimensions of peripersonal space generally correspond to the length of the arm (Carello et al., 1989; Longo \& Lourenco, 2007) or, more precisely, to the metrics of the space of engagement, as indicated by overestimations in judgements of reachability (Rochat \& Wraga, 1997; Gapenne, 1997).

A number of studies have in this respect shown that the use of a tool to reach targets situated within the subject's ambient space could bring about a reconfiguration of the ambient perceptual space, in the sense of what is perceived/estimated ${ }^{24}$ to be within or beyond reach. Targets that could not be reached without resorting to a

\footnotetext{
${ }^{21}$ Gordon \& Rosenblaum (2004) make an interesting point in their study of the ability of blinded subjects to assess the possibility of walking through doors of varying dimensions by echolocation. The conclusions were similar to those drawn by Warren \& Whang (1987) about the visual estimation of this possibility. For Kirkwood (2007), this suggests that it is the dimensions of the body (in this case its height and its width at shoulder level) that act as a metrics framework in such assessments independent of the perceptual modality under observation.

${ }^{22}$ See also Proffitt et al. (2006) and Proffitt (2006). Witt et al. (2005) draw similar conclusions, showing that the the use of a tool to reach targets only brings about a reconfiguration of the ambient space if the perceiving agent intends or anticipates having to use it. See infra.

${ }^{23}$ Witt et al. (2004), p.587.

${ }^{24}$ Here we assume that variations in the estimations provided by subjects reflect variations in their perceptual experience of distance. This view appears to be corroborated by the fact that several modes of estimation were used in the course of these studies (verbal estimation or visual estimation by moving markers in the visual field that allow a matching of egocentric distance), and that they tend moreover to converge (see in particular Witt et al., 2005).
} 
tool were estimated to be closer when the tool was used (Witt et al, 2005), which tends to suggest that the use of the tool may induce a reconfiguration of the peripersonal and the extrapersonal areas of the subject's ambient space. Similar observations were made in electro-physiological studies in macaques (Iriki et al, 1996; 2001), and in behavioural research involving line bisection tasks with healthy subjects (Longo \& Lourenco, 2006; 2007) and subjects suffering from neglect (Halligan \& Marshall, 1991; Cowey et al., 1994; Berti \& Frassinetti, 2000; Pegna et al., 2001)

The studies carried out on neglect patients provided particularly striking illustrations of the role that a tool is likely to have in the organising process of the perceptual ambient space. Neglect is a disorder of the representation of space that may affect brain-damaged individuals. Subjects suffering from neglect tend to ignore a part of their body and/or of their perceptual field, typically stimuli located in the contralesional hemispace (hemineglect) (Vallar, 1998; Bisiach \& Vallar, 2000). A task often used to assess the degree of visuo-spatial neglect is line bisection task, in which the subject is asked to locate the middle of a horizontal line placed in front of her: because the neglect subject only perceives the part of the line situated on the damaged side, she tends to place the mark at some distance from the correct spot. There is evidence suggesting that hemineglect could in some subjects be far more pronounced with respect to either peripersonal or extrapersonal space. Some patients may manifest a more severe neglect in the case of lines located in near space than with more distant lines (Halligan \& Marshall, 1991; Berti \& Frassinetti, 2000), while others manifest the reverse configuration (Coslett et al, 1993; Cowey et al., 1994; Vuilleumier et al., 1998). Indeed, it is especially to note that several other studies have demonstrated that patients showing a more pronounced neglect for near space begin to manifest the same severe deficiencies for far space if they carry out the bisection task along lines situated in the far distance with the help of a stick (Berti \& Frassinetti; Pegna et al., 2001; Ackroyd et al., 2002).

Taken as a whole, these studies suggest that accessibility, i.e. the possibilities available to the subject to reach the objects situated within her environment, may act as a metric for the perception (in this case visual) of distance $^{25}$. They also support the more general view that the subject's capacity to act within her environment structures the way in which the environment presents itself to her - the distance between myself and the things present within my environment thus proceeds from a form of rationalisation of the world by apprehending them from the standpoint of my capacity to engage with my environment: that which is 'proximate' corresponds to that which I am liable to act upon immediately, while that which is 'distant' is on the contrary that which is beyond my sphere of influence. In this sense, the perceived distance does indeed represent, as Bergson suggested, 'the extent to which ambient bodies are insured, so to speak, against the immediate action of my body $^{26}$.

\subsection{The phenomenon of assimilation of the tool within the body schema}

Another central aspect of these observations has to do with the nature of the tool that enables the apparent extension of proximate space. The fact that, in the experiments referred to here, the use of a laser pointer - as opposed to a stick - to perform the bisection of lines did not enable an extension of the neglect space from near to far space in some patients (see for example Berti \& Frassinetti, 2000) may be indicative of the need for rigidity, but it may also point to the need for a visible continuity of the tool for the extension of peripersonal space. If the proximate space in question corresponds to the subject's immediate sphere of influence upon her environment, then it is easy to understand the need for a tool that is rigid, since rigidity conditions the possibility of exerting an action on the far areas of space.

In fact, this last question returns us to the issue of the nature of the body. A number of psychologists have suggested, on the basis of these observations, that the extension of peripersonal space could be the result of the integration of the tool in question within the body schema. This possibility had in fact already been suggested by Head \& Holmes (1911), who had illustrated the point with a range of cases in which the individual relies on the extension provided by a prosthesis or a tool in her interaction with her environment (the example of the feather in the women's hats comes to mind $)^{27}$.

In contemporary psychology the notion of body schema commonly refers to a global model of body configuration (the position of bodily parts in relation to one another; dimension; shape) used to regulate posture and to control movements, and more generally to guide the various kinds of physical interaction between the subject and her environment (such as motion in a crowded area, manipulation, etc.). Head and Holmes (1911), who were among the first to make a systematic use of this notion, argued that the body schema operates as a

\footnotetext{
${ }^{25}$ See Witt et al. (2005).

${ }^{26}$ Bergson (1896), op.cit., p.15.

27 'Anything which participates in the conscious movement of our bodies is added to the model of ourselves and becomes part of these schemata: a woman's power of localisation may extend to the feather in her hat' (Head \& Holmes, 1911, p.188).
} 
standard schema of the body, which acts as a referent for the subject's perception of her body configuration in a given situation. In other words, it is a model that enables the estimation of postural changes and movements which precedes the conscious experience of the process. The current view is that the body schema is a representation in real time of the body's disposition in space (see for example: Gallagher, 1986, 2000; Gallagher \& Cole, 1995; Coslett, 1998; Maravita \& Iriki, 2004). A representation of this kind, so the argument goes, derives from the integration of somato-sensory, visual and vestibular data (tactile and proprioceptive signals), and is articulated with the motor systems to generate and control motion without having to engage in a process of conscious monitoring. By this conception, the body schema is a functional representation of the body used to regulate posture and control motion. As suggested by Pick (1908) and Head \& Holmes (1911), the postulate of this representation of the body, updated by different afferent signals or sensory-motor interactions, is needed to account for the performance of the routine motor actions of everyday life ${ }^{28}$. The speed, precision and fluidity of an everyday movement such as reaching out for a cup of coffee while reading the newspaper, and the fact that it can be performed without any associated effort of concentration and without any explicit awareness of the various parts of the body involved in the operation, suggests that this representation is constantly available and set in motion within the motor system - in short, that the body 'knows' its situation although such knowledge need not be consciously realised.

While it is indeed an integration of the tool within the body schema that underlies the phenomena observed in the studies referred to above $\mathrm{e}^{29}$, there remains nonetheless the question of the nature of the body whose body schema constitutes, according to contemporary psychology, a functional representation. In other words, what is the object of the knowledge which the perceiving/cognitive agent acquires by means of the body schema? The obvious response is to say that it is a knowledge of her body as a structure articulated in space. But this body can hardly be construed as a thing in the same way as the things situated within my immediate environment $\operatorname{can}^{30}$. My body is primarily the form of my situatedness in the world, enabling the actions which $I$ perform therein; it is, in short, something that $I$ am. In other words, while my body is indeed a spatial thing, it is equally a power that is available for use by me. But what does it mean to speak of a body schema that is the functional representation of a power? Primarily that the object of its representation will be constructed in such a way as to reflect the reach or amplitude of the range of possible actions enabled by this power.

One useful distinction might help to shed some light on this matter. On the one hand, it is possible to posit what we might call a 'static' conception of the reconfiguration of the body schema, in which it is the perception of a visible extension of the body in space by means of the tool which enables the integration of the tool within the body schema. On the other hand, it is also possible to defend a dynamic and praxiological conception which assumes that it is the reconfiguration of the possibilities of action/intervention provided by the tool that carries out this incorporation within the body schema. The interpretation of this issue given by Berti \& Frassinetti (2000) is an illustration of what we refer to here as the static conception.

By way of illustrating the inability of the laser pointer to extend the peripersonal space to the distant zones reached by the beam in the case of their hemineglect subject, Berti \& Frassinetti (2000) argued that it was the 'coding' of the tool as an extension of the hand (i.e. what they construed as an extension of the body schema) that generated the reconfiguration of the ambient space suggested by the result patterns of the bisection task. The argument is that if the laser pointer is also liable to be integrated within the user's body schema, its size, by contrast (and unlike the size of the stick), is such that it does not alter the relation between personal space (the dimensions of the body), peripersonal space (the space that is within reach) and extrapersonal space (the space that is beyond reach), which in their view is a constitutive element of the phenomena under observation. In the authors' view, the main body of evidence in support of this interpretation is provided by Iriki et al. (1996), who studied the plasticity of the visual receptive field (RF) of bimodal neurons in macaques. The macaques' repeated use of a rake to grasp objects that were beyond their reach was shown to have the following effects: (a) an expansion of the visual RF from the hand to the extremity of the tool was noted for some bimodal neurons reacting to somato-sensory stimuli confined to the hand, such that the neurons in question now reacted to visual stimuli placed near the extremity of the rake; (b) an expansion of the visual RF to the areas that could be reached with the rake was noted for some bimodal neurons reacting to somato-sensory stimuli that were located in the

\footnotetext{
${ }^{28}$ See Coslett (1998), p.529.

${ }^{29}$ The idea that tool-use leads to the integration of the tool within an individual's body schema is corroborated by the findings of recent studies of the processes of crossmodal extinction (Farnè \& Ladavas, 2000; Maravita et al., 2000, 2001, 2002a; Farnè et al., 2005 ; Legrand et al., 2007) and crossmodal interference in humans (Maravita et al., 2002b,c; Maravita et al., 2003). For instance, Farnè \& Ladavas (2000) studied a subject displaying an extinction of tactile simulations on the left hand by competing visual stimuli on the right side of the right hand, and observed that after approximately five minutes of use under visual control of a tool in the right hand to reach objects situated opposite the subject, visual stimuli at the extremity of the tool produced more extinction than before the training period.

${ }^{30}$ See Legrand et al. (2007).
} 
area of the shoulder and the neck and whose visual RF initially covered the area of ambient space that could be reached with the hand. After a learning period of several weeks, a few minutes with the tool were enough to observe this reconfiguration. The authors also demonstrated that the expansion only occurred when the macaque was actively using the rake; a passive grasp of the rake had no effect ${ }^{31}$.

However, a number of observations, especially those made by Iriki et al. (2001), present a serious challenge to this interpretation. Iriki et al. (2001) replicated the results of their previous study with a device with which the macaque in this case is not able to see its hands while it is using the tool (its hands are concealed by a plank), but can watch them on a screen set up at eye level by means of a camera used to film its hands and placed beneath the plank. The authors observed once again that the macaque's repeated use of a tool generated an expansion of the visual RF from the area situated around the hand on the screen to the area that covered the entire length of the tool. However, the experiment now included a new variation: the images of the hand and of the tool were filtered out of the picture in such a way that the only remaining element was a simple dot (a kind of computer cursor) corresponding to the extremity of the tool, in other words its point of contact. Interestingly, they noted that in this case the visual RF of the neurons under observation formed around this point. What this suggested to the authors was that the macaques treated the cursor as an extension of their body ${ }^{32}$. What these observations suggest is that what matters for the extension of the lived body/body schema in question is not the visual perception of a continuity and of a spatial extension of the visible body by means of the tool used so much as the area of the ambient space within which the subject is able to exert an action ${ }^{33}$.

In the same vein, the observations drawn by Holmes et al. (2004) demonstrating the central role played by the point of action in the extension of the body and of peripersonal space in the use of various tools suggest that the crucial factor in the reconfiguration of ambient space is the tool's determining influence on the subject's ability to act, rather than static properties such as the dimensions of the body. Maravita \& Iriki (2004) have also noted that the phenomenon of expansion of the visual RF observed by Iriki et al. (1996) concerned neurons with RFs on the arm/hand, but not with RFs on the fingers. This could be interpreted as evidence for the view that the neurones in question are sensitive to the hand as supporting a functional ability (a power of prehension) rather than as a part of the body construed as a thing or form extended in visual space. As noted by Maravita et al. (2004), the rake corresponds to "a functional extension of the hand and forearm, but not of the fingers" 34 , in so far as it only helps to reach and move distant objects but does not allow a precision grip, which is a specifically digital operation.

Taken as a whole, what these observations tend to suggest is that the body is construed as a power which enables our engagement and involvement with the world. What the bimodal neurons examined by Iriki et al. $(1996 ; 2001)$ or the body schema in neuropsychology represent is a 'body' which is only one's own to the extent that it is invested with a form of confidence which raises this body to the status of a capacity which one has at one's disposal.

This conception of the body is similar to the view proposed by Petit (2003) by way of drawing a parallel between the theory of the constitution of the body expounded by Husserl in a collection of manuscripts dating from the 1930s and a number of recent neurological observations concerning the plasticity of somatosensory cortical maps. In Petit's view, Husserl's attempt to reinterpret 'the experience of the body as the organ of the intervention of the I with the world ${ }^{35}$ presents striking similarities with these neurological observations to the extent in particular that both suggest a conception of the body that is at radical odds with the widespread static conception, which tends to reduce the experienced or 'represented' body in the brain to a representation of the physical body ${ }^{36}$. Husserl's late turnaround in his conception of the body is illuminating to the extent that it suggests a meaning of the body that is no longer construed by the consciousness that inhabits it as an object (Körper) or as something felt, as an enabling support for sensations (Leib), but rather as a power. To this extent,

\footnotetext{
${ }^{31}$ Several studies of the effects of tool-use in human subjects corroborate the idea of the necessity of active use of the tool for the phenomenon of reconfiguration of lived body and space to occur. For instance Farnè \& Ladavas (2000) observed that the extension of the space of visuo-tactile extinction to the end of the tool gradually dissipated when the subject merely held the tool without putting it to active use, and disappeared altogether after five to ten minutes. In the same vein, Farnè et al. (2005) observed in a patient suffering from visuo-tactile extinction that passively holding the tool was not enough to produce such an extension of peripersonal space (an extension inferred on the basis of the observed extinction patterns), and that an active use of the tool was required. See also Legrand et al. (2007).

${ }^{32}$ See also Maravita \& Iriki (2004), p.81.

${ }^{33}$ Maravita \& Iriki also raise this issue (2004) in the following terms: 'When reaching with a long tool, is it the appearance of a body extension or the understanding about the tool's "effective operational distance" that is essential for tool-to-body assimilation [...]?' (p.85).

${ }^{34}$ Maravita et al. (2004), p.81.

${ }^{35}$ Petit (2003), p.146.

${ }^{36}$ Petit (2003), p.141.
} 
Husserl paved the way for the articulation of a third meaning of the body tending towards praxis - possibly a more fundamental meaning than the two existing meanings. The Husserlian conception also bears a striking resemblance to Merleau-Ponty's conceptualisation of the body, in which my body, in the pre-reflexive 'everydayness' in which $I$ primarily live before it is objectified, constitutes a 'power for a number of familiar actions in my surroundings construed as a set of manipulanda ${ }^{37}$. For Merleau-Ponty, the lived body (understood as the organ of action in the world) and the ambient world form a system, in such a way that 'my arm supports the actions that are so deeply familiar to me, my body constitutes a determined power of action whose reach and field of application is already known to me, and my surroundings are a set of potential applications of this power ${ }^{38}$. For Merleau-Ponty, it is this 'knowledge' of the body which is conveyed by the body schema, inasmuch as my body "cor-responds" to the affordant, usable or summonable nature of the perceived ambient world, whether it be its spatial organisation or the functional meaning through which its structures and the objects which are contained therein are apprehended.

\section{The nature of practical possibilities in the process of constitution of the ambient world.}

By way of a provisional conclusion concerning the various issues addressed in this paper, let us note first of all that the preceding argument pertaining to space and distance evidently presents a challenge to the assumption of any strict isolation of 'motor' and 'perceptual' phenomena. Indeed, the meaning of the world experienced by the subject is to be found in a relation of presupposition with respect to motor activity and the modalities of interaction with the world (such as motion, agency, collision, manipulation, etc.). The object that I perceive at a distance from me owes this distance to my capacity to reach it. Nonetheless, since this is an issue which concerns motor abilities and practical dispositions rather than effectively implemented actions, the object of inquiry needs to shift away from theories of active perception, in particular sensory-motor theories of perception ${ }^{39}$, which envisage perception as something enacted by actual movements. Rather, the focus of the inquiry ought to become the role performed by potential action in the constitution of perceptual experience. It is not enough merely to account for how action shapes the constitution of the ambient world manifested in perception typically the question as to how invariants are extracted from the active variation of sensory fields. Future work on the topic will need to account for the way in which the meaning of the diversely structured world that offers itself to the subject is fostered by reference to the subject's practical possibilities - that is, the various modes of dialogue that might be engaged in an interaction with this world and these things. This is not to say that the perceptual relation to a field of appearing objects does not rest on the recognition/extraction/stabilisation of typicities in moto-sensorial variations, but that what is perceived by the subject (or in the terms of Husserlian phenomenology: the pole of meaning that is the object of perceptual intentionality) cannot be accounted for by resorting to such typicities. Sensory-motor activity affords access to an object to the extent that it refers back to a series of possibilities in which I live and which matter to me - and which constitute a form of rationality from which the ambient world draws its meaning. Within such a framework, the meaning of the body for the subject who is that body may be understood.

However, the hermeneutic function performed by the subject's practical possibilities manifestly plays a part in a coming-into-being where such possibilities help to implement principles of organisation of the perceptual field as well as a semiotics of the ambient world, which eventually stabilise and acquire a form of autonomy. Once again, the issue is to take the measure of the fundamentally historical character of the perceiving agent ${ }^{40}$. As a result of habit, of the effective availability of dispositions for interaction, the hermeneutic principles corresponding to them appear to undergo a kind of fossilization ${ }^{41}$, in such a way that the loss of these aptitudes is no longer enough to extract them from the hermeneutic process which acts as a regulatory principle in the agent's understanding of her ambient world. The thing remains graspable, within reach, even if I no longer have a hand with which to grasp it. The dispositions performing this hermeneutic function cannot therefore be equated with possibilities that are effectively available to the agent. Once again, this would be tantamount to reducing the possible to the actual. In fact, the particular dispositions referred to here may very well correspond to previously effective possibilities that are no longer effective. Evidence for this view

\footnotetext{
${ }^{37}$ Merleau-Ponty (1945), p.122.

${ }^{38}$ Merleau-Ponty (1945), p.122.

${ }^{39}$ See for example O'Regan \& Noe (2001) and Lenay (2006).

${ }^{40}$ See Rosenthal (1993), p.203.

${ }^{41}$ Iriki et al. (1996) provide a neurological verification of this process: the persistence of the extension of the visual receptive field of bimodal neurones when the monkey is no longer making use of the tool may be interpreted as one such example of fossilization - in this case admittedly reversible and restricted to a very short period (a few minutes) - of the hermeneutic function associated with the capacity to reach objects with the tool.
} 
is provided by a wide range of cases, such as the example of the amputated subject suffering from phantom limb syndrome (and thus still relying upon the availability of her $l i m b^{42}$ ) or indeed the case of the paralytic subject who, though not disposing of the possibility of motion, continues to experience a spatialised world still characterised by extensive depth - in other words a world addressing itself to the subject conceived as an agent possessing the ability to move.

In this sense, the only approach that is likely to solve the issue of the entrenchment of the process of constitution of the ambient world within the agent's possibilities will be a historical and genetic approach. Because the hermeneutic function performed by the range of practical possibilities in the process of perceptual constitution is the outcome of a specific (individual and supra-individual) history, it is not subservient to the actual state in which the subject finds herself. The effective loss of possibility proves to be inadequate for the purposes of eradicating this possibility from the 'understanding' (in the Heideggerian sense of the term) that underlies the constitution of the ambient world. Whereas a machine might have updated itself automatically, man is always lagging one step behind his actuality. Perceptual hermeneutics thus operates with a host of inherited dispositions.

The issue of the conditions enabling the constitution of the ambient world as an arrangement of usable structures (a system of affordances) cannot be properly addressed solely by analysing individual processes, whether phenomenological or psycho-biological, to use J. Paillard's term ${ }^{43}$. It will necessarily require a phylogenetic inquiry - in other words an examination of the articulation of the individual process of constitution of the ambient world and of phylogenetic evolution that might be described as a process of anamnesis or as the re-appropriation of a means of relating to the ambient world entrenched within specific structures.

This last idea is equally important in Gibson's ecological theory of perception, which contrasts with a traditional conception that takes the notion of sensation or sensation data as its conceptual starting-point. In Gibson's view, the process of 'synthesis' required for the perception of a world is rooted in the very structure of the perceptual apparatus. The product of a phylogenetic process need not be reiterated in the living present of perception. The very selectivity of the perceptual apparatuses (that to which they may or may not be sensitive in other words what they 'retain' from the world) is already a kind of synthesis, a means of distinguishing singularities in the infinite realm of possibilities. By contrast, the traditional psychological view is that synthesis operates on sensory data or sensory-motor flow by means of so-called 'high-order' cognitive processes that serve to integrate the data by way of constructing the signifying world that is effectively experienced by the conscious subject ${ }^{44}$.

The approach of the ecological theory or the conception of synthesis advocated by Merleau-Ponty (1945) - which present a number of striking parallels - are therefore not hostile to the notion of synthesis, although they do take issue with the intellectualist conception of synthesis. If an animal (and a fortiori if the animal in question is a human being) can have a direct and unmediated perception of the data provided by the environment as 'affordances', it is because its perceptual apparatus is the outcome of a history, both individual and supra-individual. In our view, this is one of the most significant conclusions to be drawn from the Gibsonian notion of direct and unmediated perception. It is to the extent that the temporality upon which its construction is deployed is phylogenetic and in no way reducible to the subject's time-scale that the perception of meaning is direct and unmediated, rather than the result of the effect of various epistemic mediators on raw sensory data (Turvey \& Shaw, 1979).

\section{Acknowledgement}

The authors are grateful to Robert Reay-Jones for translating this text from the original French. The authors are also grateful to the reviewers for their comments, which helped to improve the overall quality of the final draft of this paper and opened new avenues of thought for future research.

\footnotetext{
${ }^{42}$ See the cases cited by Simmel, 1958; Poeck, 1964; Melzack, 1989; Merleau-Ponty, 1945; Gallagher, 2000. For Merleau-Ponty, the experience of the amputated subject suffering from the phantom limb syndrome consists in relying on a power which is no longer at her disposal, or 'to remain open to the range of actions which only an arm is able to perform, (...) to maintain the practical field as it was before amputation' (Merleau-Ponty, 1945, p.97).

${ }^{43}$ Paillard (1987).

${ }^{44}$ Turvey (1974) provides a useful summary of this view, contrasting the Gibsonian idea of a direct and unmediated perception of the signifying data conveyed by the environment with a theorisation of 'constructive' perception. See in particular Turvey (1974), p.166.
} 


\section{References}

Ackroyd, K., Riddoch, M.J., Humphreys, G.W., Nightingale, S., Townsend, S. (2002). Widening the sphere of influence: using a tool to extend extrapersonal visual space in a patient with severe neglect. Neurocase, 8, 1-12.

Bergson, H. (1896). Matière et mémoire. Paris, PUF, $7^{\mathrm{meme}}$ édition, « Quadrige », 2004.

Berkeley, G. (1709). Essai pour une nouvelle théorie de la vision. Trad. collective sous la direction de G. Brykman, Euvres, Tome I, Paris, PUF, 1985.

Berti, A. \& Frassinetti, F. (2000). When far becomes near: Remapping of space by tool use. Journal of cognitive neuroscience, $12,415-420$.

Bisiach, E. and Vallar, G. (2000). Unilateral neglect in humans. In Boller, F. \& Grafman, J. (eds), Handbook of Neuropsychology, 459-502.

Carello, C., Grosofsky, A., Reichel, F. D., Solomon, H. Y., \& Turvey, M. T. (1989). Visually perceiving what is reachable. Ecological Psychology, 1, 27-54.

Changeux, J.P., Ricœur, P. (2000). Ce qui nous fait penser. La nature et la règle. Ed. Poches Odile Jacob.

Coello, Y., Delevoye-Turrell, Y. (2007). Embodiment, spatial categorisation and action. Consciousness and Cognition, 16, 667-683.

Coslett, H.B. (1998). Evidence for a disturbance of the body schema in neglect. Brain and Cognition, 37, 527544.

Coslett, H.B., Schwartz, M.F., Goldberg, G., Haas, D., Perkins, J. (1993). Multi-modal hemispatial deficits after left hemisphere stroke: a deficit in attention? Brain, 116, 527-554.

Cowey, A., Small, M., and Ellis, S. (1994). Left visuo-spatial neglect can be worse in far than in near space. Neuropsychologia, 37, 1-6.

Farné, A. \& Làdavas, E. (2000). Dynamic size-change of hand peripersonal space following tool use. Neuroreport, 11, 1645-1649.

Farnè, A., Bonifazi, S., Làdavas, E. (2005). The role played by tool-use and tool-length on the plastic elongation of peri-hand space: a single case study. Cognitive Neuropsychology, 22 (3-4), 408-418.

Gallagher, S. (1986). Body image and body schema: A conceptual clarification. Journal of Mind and Behavior, 7, 541-554.

Gallagher, S. (2000). Phenomenological and experimental research on embodied experience. Atelier phénoménologie et cognition, Phenomenology and Cognition Research Group, CREA, Paris.

Gallagher, S., \& Cole, J. (1995). Body image and body schema in a deafferented subject. Journal of Mind and Behavior, 16, 369-390.

Gapenne, O. (1997). Evaluation de l'atteignabilité d'une cible chez l'enfant de 3 à 6 ans. In J. Lorenceau, A. Streri, B. Victorri \& Y.M. Visetti (Eds), Actes de la VI ${ }^{\text {ème }}$ école d'été de l'ARCO «Le mouvement : des boucles sensori-motrices aux représentations cognitives et langagières », 101-112.

Gibson, J.J. (1977). The theory of affordances. In: Shaw, E.E. et Bransford J. (Eds), Perceiving, Acting and knowing, Hillsdale, N.J.: Lawrence Erlbaum Associates.

Gibson, J.J. (1979). The ecological approach to visual perception. Hillsadle, N.J.: Lawrence Erlbaum Associates, 1986.

Gordon, M.S. \& Rosenblum, L.D. (2004). Perception of sound-obstructing surfaces using body-scaled judgments. Ecological Psychology, 16 (2), 87-114.

Halligan, P. \& Marshall, J.M. (1991). Left neglect for near but not for far space in man. Nature, 350, 498-500.

Head, H. \& Holmes, G. (1911). Sensory disturbances from cerebral lesions. Brain, 34, 102-254.

Heidegger, M. (1927). Etre et temps. Trad. François Vezin, Paris, Gallimard, 1986.

Heidegger, M. (1931). Aristote. Métaphysique Thêta 1-3. De l'essence et de la réalité de la force (GA33). Traduction Bernard Stevens et Pol Vandevelde. Paris, Gallimard, 1991.

Holmes, N.P., Calvert, G.A., Spence, C. (2004). Extending or projecting peripersonal space with tools? Multisensory interactions highlight only the distal and proximal ends of tools. Neuroscience Letters, 372, 62-67.

Iriki, A., Tanaka, M., Iwamura, Y. (1996). Coding of modified body schema during tool use by macaque postcentral neurones. Neuroreport, 7, 2325-2330.

Iriki, A., Tanaka, M., Obayashi, S. and Iwamura, Y. (2001). Self-images in the videomonitor coded by monkey intraparietal neurons. Neuroscience Research, 40, 163-173.

Jeannerod, M. (2001). Simulation of action as a unifying concept for motor cognition. In Johnson, S.H. (Ed.), Cognitive neuroscience. Perspectives on the problem of intention and action, Cambridge, MA: MIT Press. 
Kirkwood, B.C. (2007). Information from impact sounds: normal and impaired hearing. Ph.D. Thesis, Technical University of Denmark.

Legrand, D., Brozzoli, C., Rossetti, Y., Farnè, A. (2007). Close to me: Multisensory space representations for action and pre-reflexive consciousness of oneself-in-the-world, Consciousness and Cognition, 16, 687-699.

Lenay, C. (2006). Enaction, externalisme et suppléance perceptive. Intellectica, 43, 27-52.

Longo, M.R., Lourenco, S.F. (2006). On the nature of near space: Effects of tool use and the transition to far space. Neuropsychologia, 44, 977-981.

Longo, M.R., Lourenco, S.F. (2007). Space perception and body morphology: extent of near space scales with arm length. Experimental brain research, 177 (2), 285-290.

Maravita, A., Spence, C., Clarke, K., Husain, M. Driver, J. (2000). Vision and touch through the looking glass in a case of crossmodal extinction. Neuroreport, 11, 3521-3526.

Maravita, A., Husain, M., Clarke, K., Driver, J. (2001). Reaching with a tool extends visual-tactile interactions into far space: Evidence from cross-modal extinction. Neuropsychologia, 39, 580-585.

Maravita, A., Clarke, K., Husain, M., Driver, J. (2002a). Active tool-use with contralesional hand can reduce crossmodal extinction of touch on that hand. Neurocase. 8, 411-416.

Maravita, A., Spence, C., Sergent, C., Driver, J. (2002b). Seeing your own touched hands in a mirror modulates cross-modal interactions. Psychological Science, 13, 350-355.

Maravita, A., Spence, C., Kennett, S., Driver, J. (2002c). Tool-use changes multimodal spatial interactions between vision and touch in normal humans. Cognition, 83, B25-B34.

Maravita, A., Spence, C., Driver, J. (2003). Multisensory integration and the body schema: close to hand and within reach. Current Biology, 13, R531-R539.

Maravita, A. \& Iriki, A. (2004). Tools for the body (schema). Trends in Cognitive Sciences, 8 (2), 79-86.

Mark, L.S. (1987). Eyeheight-scaled information about affordances: A study of sitting and stair climbing. Journal of Experimental Psychology, 13, 361-370.

Mark, L.S., \& Vogele, D. (1987). A biodynamic basis for perceived categories of action: A study of sitting and stair climbing. Journal of Motor Behavior, 19, 367-384.

Melzack, R. (1989). Phantom limbs, the self and the brain. Canadian Psychology, 30, 1-16.

Merleau-Ponty, M. (1945). Phénoménologie de la perception, Paris, Gallimard, Collection Tel.

O'Regan, K. \& Noe, A. (2001). A sensorimotor account of vision and visual consciousness. Behavioral and Brain Sciences 24(5):35.

Oudejans, R.R., Michaels, C.F., Van Dort, B., Frissen, E.J.P. (1996). To cross or not to cross: The effect of locomotion on street-crossing behavior. Ecological psychology, 8(3), 259-267.

Pacherie, E. (1997). Du problème de Molyneux au problème de Bach-y-Rita. In Proust, J. (ed.), Perception et Intermodalité, Approches actuelles du Problème de Molyneux, Paris, PUF.

Paillard, J. (1987). Vers une psychobiologie de l'intentionnalité ? In: Laurent, M., Therme, P. (Eds.), Recherches en A.P.S. 2, 163-194.

Paillard, J. (1994). La conscience. In: Richelle, M., Requin, J., Robert, M. (Eds), Traité de psychologie expérimentale, chap. VI.6 (639-684), Paris, Presses Universitaires de France.

Patočka, J. (1995). Papiers phénoménologiques. Traduction Erika Abrams. Grenoble, Jerôme Millon.

Pegna, A. J., Petit, L., Caldara-Schnetzer, A.-S., Khateb, A., Annoni, J.-M., Sztajzel, R., Landis, T. (2001). So near yet so far: Neglect in far or near space depends on tool use. Annals of Neurology, 50, 820-822.

Petit, J.L. (2003). La spatialité originaire du corps propre : phénoménologie et neurosciences. Géométrie \& Cognition, numéro spécial publié sous la dir. de G. Longo, Revue de synthèse, $5^{\text {ème }}$ série, année 2003, t. 124, 2004, 139-171.

Pick, A. (1908). Uber Störungen der Orientierung am eigenen Körper. In: Arbeiten aus der deutschen psychiatrischen Universitatsklinik in Prag. Berlin: Karger, 1-19.

Poeck, K. (1964). Phantoms following amputation in early childhood and in congenital absence of limbs. Cortex, $1,269-275$.

Poincaré, H. (1907). La Science et l'hypothèse. Paris, Flammarion.

Proffitt, D.R. (2006). Embodied perception and the economy of action. Perspectives on psychological science, 1(2), 110-122.

Proffitt, D.R., Stefanucci, J., Banton, T., Epstein, W. (2003). The role of effort in perceiving distance. Psychological Science, 14, 106-113. 
Proffitt, D.R., Stefanucci, J., Banton, T., Epstein, W. (2006). Reply to Hutchinson and Loomis. The Spanish Journal of Psychology, 9, 340-342.

Rochat, P. and Wraga, M. (1997). An account of the systematic error in judging what is reachable. Journal of Experimental Psychology: Human Perception and Performance, 23, 199-212.

Rosenthal, V. (1993). Cognition, vie et... temps. In: Intellectica, Biologie et cognition, n 16, 1993/1, 175-207.

Ruyer, R. (1952). Néo-finalisme. Paris, PUF.

Sartre, J.-P. (1943). L'être et le néant. Paris, Gallimard.

Simmel, M.L. (1958). The conditions of occurrence of phantom limbs. Proceedings of the American Philosophical Society, 102, 492-500.

Simondon, G. (1964-1965). Cours sur la perception. Les éditions de la transparence, 2006.

Solomon, H.Y. \& Turvey, M.T. (1988). Haptically perceiving the distances reachable with handheld objects. Journal of Experimental Psychology: Human Perception and Performance, 14, 404-427.

Thomas G. J. (1984). Memory : Time binding in organisms. In: Squire, L. R. \& Butters, N. (eds), Neuropsychology of memory, chap. 34 (374-384), London, The Guilford Press.

Turvey, M. T. (1974). Constructive theory, perceptual systems, and tacit knowledge. In: Weimer, W.B., Palermo, D.S. (eds), Cognition and. the Symbolic Processes (165-180), Hillsdale, NJ: Lawrence Erlbaum Associates.

Turvey, M. T., \& Shaw, R. E. (1979). The primacy of perceiving: An ecological reformulation of perception for understanding memory. In Nilsson, L.G. (Ed.), Perspectives on memory research, Hillsdale, NJ: Lawrence Erlbaum Associates, 167-222.

Vallar, G. (1998). Spatial hemineglect in human. Trends in Cognitive Sciences, 2, 87-97.

Vuilleumier, P., Valenza, N., Mayer, E., Reverdin, A., Landis, T. (1998). Near and far visual space in unilateral neglect. Annals of Neurology, 43, 406-410.

Warren, W.H. \& Whang, S. (1987). Visual guidance of walking through apertures: Body-scaled information for affordances. Journal of Experimental Psychology: Human Perception and Performance, 13, 371-383.

Warren, W.H. (1984). Perceiving affordances: Visual guidance of stair climbing. Journal of Experimental Psychology: Human Perception and Performance, 10, 683-703.

Witt, J.K., Proffitt, D.R., \& Epstein, W. (2004). Perceiving distance: A role of effort and intent. Perception, 33, 577-590.

Witt, J.K., Proffitt, D.R., and Epstein, W. (2005). Tool use affects perceived distance, but only when you intend to use it. Journal of experimental psychology: Human perception and performance, 31 (5), 880-888. 